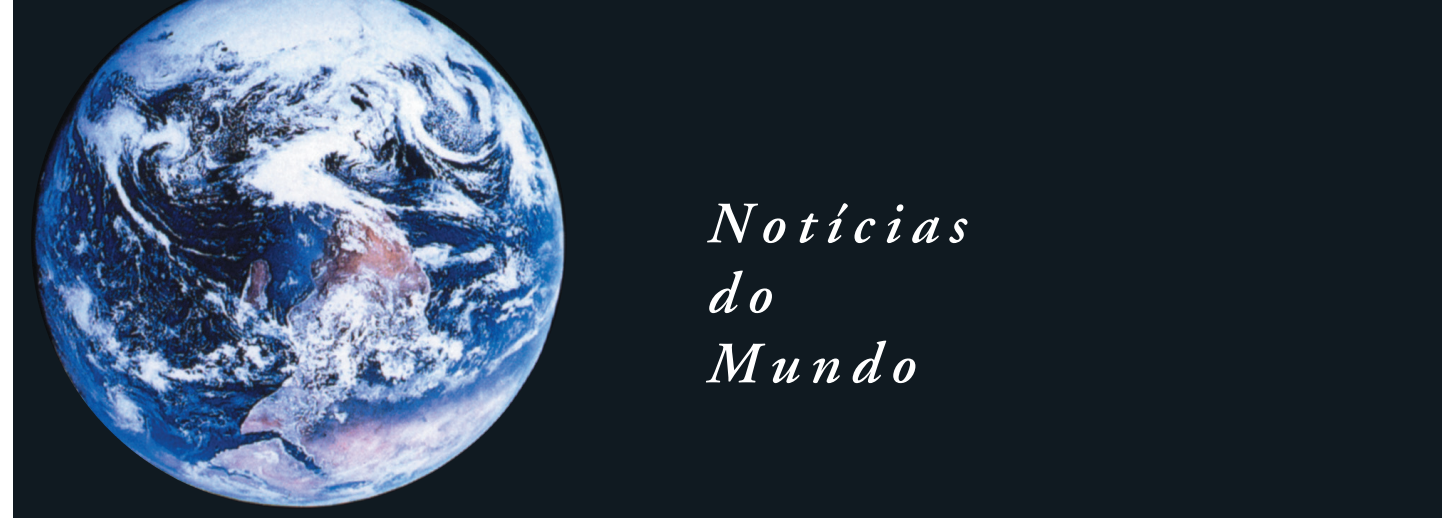

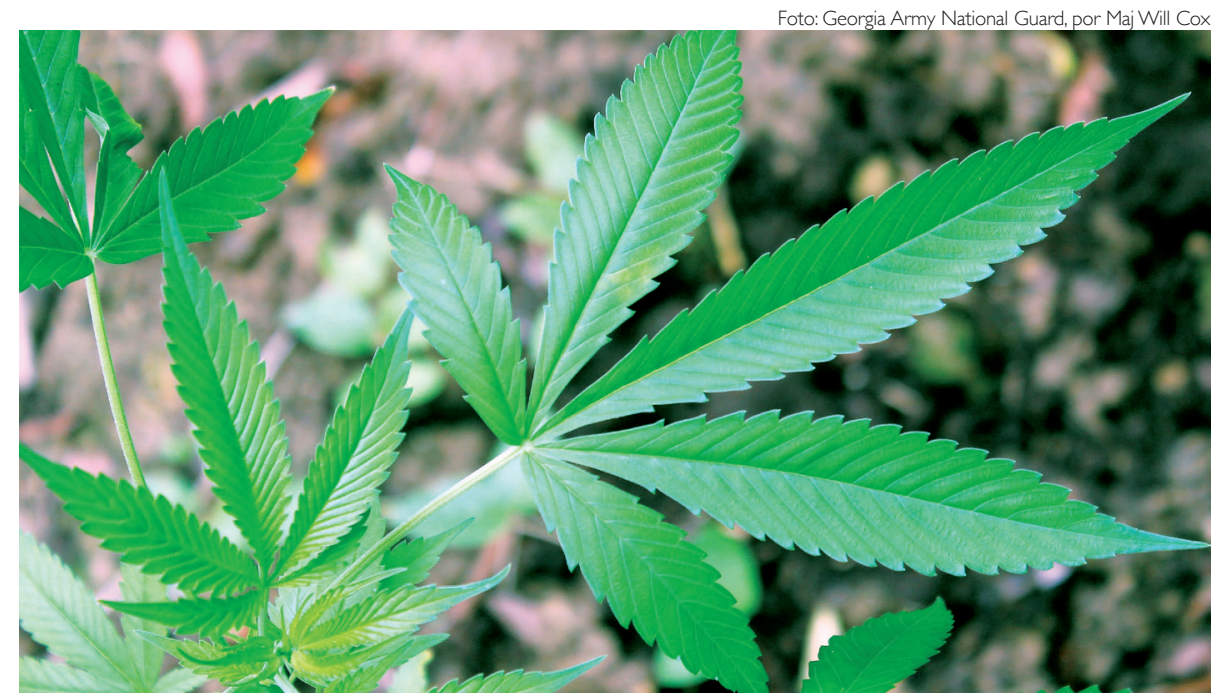

Oito estados norte-americanos descriminalizaram o uso da maconha nas eleições de 2016

LEGISLAÇÃO

\section{Descriminalização da maconha: 0 que muda no consumo}

As eleiçôes realizadas em novembro do ano passado dos Estados Unidos, que levaram Donald Trump à presidência, também definiram questôes importantes relativas ao uso da maconha no país. $\mathrm{Na}$ ocasiāo, eleitores de nove estados responderam sobre o uso da Cannabis na cédula de votação. Após essa consulta, Califórnia, Massachusetts, Nevada e Maine legalizaram o uso recreativo da maconha. No Arizona a proposta foi rejeitada. Em outros quatro estados - Flórida, Arkansas, Montana e Dakota do Norte - foi aprovado o uso medicinal da planta.
Muitos estudos buscam entender como a descriminalização e a legalização podem impactar no consumo da planta. Na Califórnia, por exemplo, o uso medicinal da maconha é legal desde 1996, mas a substância já havia sido descriminalizada no estado 20 anos antes. De acordo com a primeira avaliação oficial sobre o uso da Cannabis, realizada pelo Departamento de Narcotráfico e Abuso de Drogas do estado da Califórnia onze meses após a descriminalização, houve no período um aumento de $8 \%$ para $35 \%$ da proporção de adultos que relataram ter utilizado a planta. Outros estados pioneiros na descriminalização também apresentaram um aumento na frequência de relatos de uso da maconha, mas a prevalência aumentou a taxas semelhantes ou maiores nos estados que mantiveram penalidades mais severas. Em revisão publicada em 1989 na Journal of Public Health Policy, por Eric W. Single, o autor frisa que "a maior limitação desses estudos iniciais [sobre a descriminalização e a prevalência de uso da maconha] foi a falta de grupos controles ou dados comparativos que indicassem uma estimativa de quanto seria a expectativa das taxas de uso se não houvesse mudança na lei”.

Sidarta Ribeiro, coordenador do Instituto do Cérebro da Universidade Federal do Rio Grande do Norte, pondera que a legalização strictu sensu ainda é bem recente. "Em casos de descriminalização como Portugal e Holanda, que já têm muitos anos de implementação, o consumo ficou estável ou aumentou logo no início, mas pouco depois voltou aos níveis anteriores ou caiu abaixo deles. No caso do Colorado e do Uruguai, de efetiva legalização, ainda não foi detectado aumento significativo do consumo", afirma. "É importante considerar que a Cannabis legalizada competirá com substâncias mais perigosas para a sociedade, como o álcool. Os dados preliminares na Califórnia pós-legalização sugerem redução nos acidentes de carro por embriaguez alcoólica”, acrescenta o pesquisador.

O processo de descriminalização e/ ou legalização da maconha ocorreu de maneira diversa em cada estado norte-americano. Em Washington, a maconha para uso recreacional deve ser 


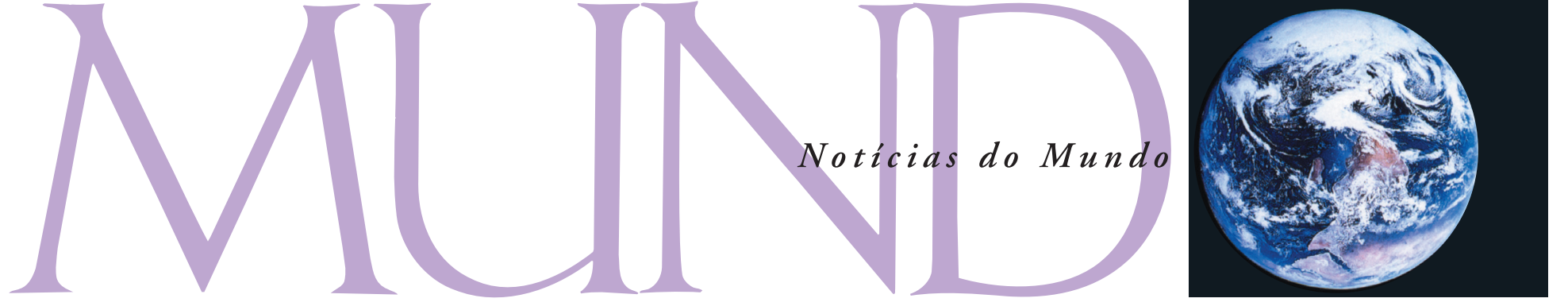

adquirida de comerciantes cadastrados, enquanto no distrito de Columbia não existem comerciantes, mas a população pode cultivar a maconha em casa. Cada estado também define critérios para o tipo de maconha que pode ser cultivada ou comercializada, afinal, o produto não é uniforme. A planta pode se desenvolver de maneiras diferentes dependendo da variedade genética, temperatura, condições de cultivo e luminosidade. E isso impacta na potência da planta, que é medida pela quantidade do princípio ativo tetrahidrocanabinol (THC). Em relação às faixas etárias, a legalização da maconha não tem afetado o uso por jovens e adolescentes, mas os adultos aumentam o consumo experimental, de acordo com oúltimo levantamento nacional norte-americano, realizado em 2015, para o uso de drogas lícitas e ilícitas. Há uma preocupação, no entanto, com um aumento significativo do uso de maconha entre usuários pesados da substância e dependentes de drogas de abuso. Estudo publicado em maio deste ano na Annual Review ofClinical Psychologysugere que o grupo de indivíduos dependentes de drogas pode ser particularmente sensívelà mudança da lei.

IMPORTÂNCIA DO DEBATE O Instituto Nacional sobre Abuso de Drogas de Abuso (NIDA, na sigla em inglês), órgão do governo norte-americano, define que o uso de maconha pode levar ao desenvolvimento de problemas médicos e, em alguns casos, à

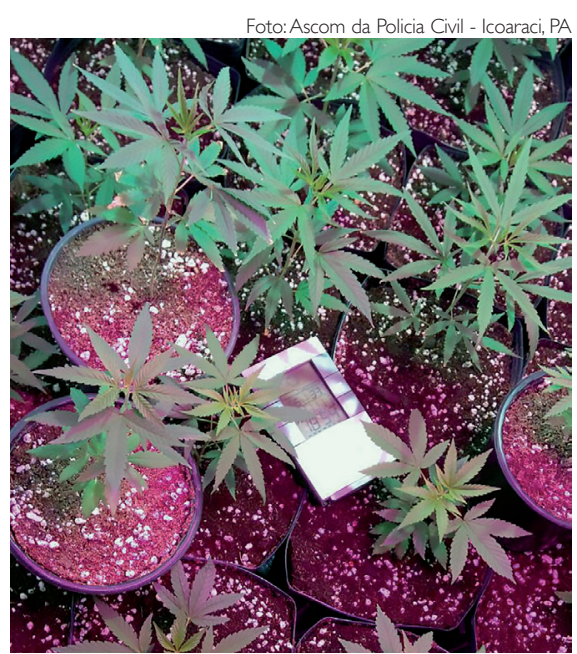

Em boa parte dos casos descriminalização não fez o consumo aumentar

dependência. "Existe razoável consenso de que aproximadamente 9\% dos usuários de Cannabis desenvolvem algum tipo de dependência, um índice bem abaixo do álcool $(\sim 15 \%)$ e do tabaco ( $-30 \%)$ ", explica Ribeiro. Segundo ele, como toda droga, a Cannabis tem grupos de risco e a proibição dificulta o esclarecimento desses grupos. "Do ponto de vista do usuário (medicinal, recreativo ou religioso), a legalização e regulamentação (de teores, prazo de validade, contaminantes, local de compra seguro, pagamento de impostos) é estritamente necessária para possibilitar um uso seguro", acredita.

Outra preocupação sobre o uso da maconha é a sua relação com o aparecimento de doenças psiquiátricas. "Por exemplo, pessoas com tendências psicóticas devem evitar Cannabis com muito THC e pouco canabidiol (CBD), mas podem se medicar com cannabis de pouco THC e muito CBD (compostos químicos da Cannabis que não é psicoativo)", explica Ribeiro. Um estudo publicado no ano passado no The American Journal of Drug and Alcohol Abuse descreve que a maconha pode desencadear o aparecimento de esquizofrenia em indivíduos com predisposição genética para a doença. Por outro lado, pacientes com esquizofrenia que fizeram uso da maconha durante a adolescência exibem melhor função cognitiva quando comparados a pacientes esquizofrênicos que não fizeram uso da planta. Isso mostra que a relação entre o uso da maconha e o aparecimento de uma psicose é mais complexa do que imaginado.

Um estudo publicado na revista $\mathrm{Na}$ ture Medicineem maio deste ano mostrou que um tratamento com baixas doses de THC foi capaz de reverter o declínio cognitivo em camundongos idosos. Dentre tantos usos medicinais da maconha demonstrados pela ciência, a recuperação do sinal canabinóide em indivíduos senis pode ser uma estratégia poderosa para combater os déficits cognitivos decorrentes do envelhecimento ou de doenças neurológicas como o Alzheimer e o Parkinson. Esse tipo de descoberta mostra quão importante são os esforços mundiais para continuar o debate sobre a descriminalização e regulamentação do uso da maconha e de seus componentes.

Karina Possa Abrahão 